\title{
Persistent cough in nonsmokers
}

\author{
VICTOR HOFFSTEIN MD \\ Department of Medicine, St Michael's Hospital, University of Toronto, Toronto, Ontario
}

\section{Hoffstein. Persistent cough in nonsmokers. Can Respir J 1994; 1(1):40-47.}

OBJECTIVE: The purpose of this study was to test the hypothesis that, using Irwin's protocol, the majority of nonsmokers with persistent cough can be diagnosed and treated successfully.

DESIGN: Retrospective review of patients referred for the investigation of chronic cough.

SETTING: Referral out-patient practice of a hospital-based pulmonary physician.

PATIENTS: There were 228 patients who satisfied the following entry criteria for inclusion in the data analysis: cough longer than four weeks; nonsmoker; normal chest radiograph; and completion of the required investigations. A total of 198 patients completed the required investigations and returned for the final follow-up visit.

INTERVENTIONS: Diagnostic tests included chest radiographs, pulmonary function tests, radiographs of the sinuses, barium swallow and fibreoptic bronchoscopy.

Main Outcome Measures: Status of cough at the time of final follow-up visit, classified according to four levels: resolved, improved, unchanged or worse.

RESULTS: The diagnosis was established in $91 \%$ of patients. The most common diagnoses (alone or in combination) were postnasal drip (26\%), asthma (25\%), gastroesophageal reflux $(24 \%)$, postinfectious cough $(21 \%)$, and cough due to angiotensin-converting enzyme inhibitors (6\%); none had an occult malignancy and one patient had endobronchial tuberculosis. The initial diagnostic impression was best in patients with postinfectious cough $(100 \%)$ and worst in patients with asthma $(25 \%)$. The outcome of specific therapy was successful in $91 \%$ of patients.

CONCLUSIONS: In the majority of nonsmoking adults cough can be diagnosed and treated successfully, most causes are relatively 'benign' and the initial clinical impression may be quite misleading, particularly in cough-variant asthma.

Key Words: Asthma, Chronic cough, Nonsmokers, Postnasal drip

\section{Toux persistante chez des non-fumeurs}

OвJECTIF : Cette étude a pour objet de vérifier l'hypothèse selon laquelle l'utilisation du protocole d'Irwin permet de poser un diagnostic chez la majorité des non-fumeurs souffrant de toux persistante et de les traiter avec succès.

MODÈLE : Étude rétrospective de patients adressés pour investigation d'une toux chronique.

ConTeXte : Consultations externes d'un centre spécialisé où pratique un pneumologue hospitalier.

Patients : Deux cent vingt-huit patients remplissaient les critères d'admission suivants pour être inclus dans l'analyse des données: toux persistant plus de 4 semaines, non-fumeur, radiographie pulmonaire normale, ayant subi tous les examens demandés. Au total, 198 patients avaient passé tous les examens demandés et s'étaient présentés à la dernière visite de suivi.

INTERVENTIONS : Les tests diagnostiques incluaient des radiographies pulmonaires, des épreuves de fonction respiratoire, des radiographies des sinus, une gorgée barytée et une fibroscopie bronchique.

Principaux Indicateurs Des Résultats : L'évolution de la toux, lors de la dernière visite de suivi, a été classée selon 4 états: a disparu, s'est améliorée, est stationnaire, s'aggrave.

RéSUltats: Le diagnostic a été établi chez $91 \%$ des patients. Les diagnostics les plus fréquents (seuls ou associés) étaient l'écoulement nasal postérieur (26\%), l'asthme (25\%), le reflux gastrooesophagien (24\%), la toux postinfectieuse (21\%) et celle causée par les inhibiteurs de l'enzyme de conversion de l'angiotensine (6\%). Aucun patient ne souffrait d'un cancer occulte tandis qu'un seul patient souffrait d'une tuberculose endobronchique. Le diagnostic initial présumé s'est confirmé le plus souvent chez les patients souffrant de toux postinfectieuse $(100 \%)$ et le moins souvent chez les patients souffrant d'asthme (25\%). Quatre-vingtonze pour cent des patients ont répondu à une thérapie spécifique. Conclusions : Chez la majorité des adultes non-fumeurs, la toux peut être diagnostiquée et traitée avec succès. La plupart des causes sont relativement bénignes. L'impression clinique initiale peut être trompeuse, surtout dans les cas d'asthme où la toux est prépondérante. 
$\mathrm{P}$ ERSISTENT COUGH CAN BE VERY FRUSTRATING FOR THE patient and physician, but a systematic approach to this problem will frequently lead to specific diagnosis and institution of treatment. Such an approach, based on the location of cough receptors, the anatomy of the reflex arc and the physiology of cough has been described by Irwin and colleagues (1-3). The central idea of this anatomic diagnostic protocol is that, knowing the location and density of cough receptors, it is possible to limit the diagnostic considerations and necessary investigations to only relatively few pulmonary and nonpulmonary entities.

This protocol was applied to two large groups of adult patients and found to have a diagnostic success rate ranging from 88 to $98 \%$ (4,5). Both studies, however, included smokers and patients with abnormal chest radiographs, which could bias the results in favour of a higher proportion of patients with chronic bronchitis and parenchymal lung disease. Furthermore, it may be argued that this high success rate is critically dependent on the type of patient referred to a specialist, pattern of referral (by general practitioners or other specialists), seasonal factors, local climate, etc. Consequently, since cough is such a common problem, it may be of interest to validate Irwin's protocol (1) in other patient populations.

The present study was undertaken to test the usefulness of Irwin's protocol (1) in the largest group of patients studied to date, all of whom complained of persistent cough, came from a large urban environment (Toronto), were nonsmokers and had normal radiographs of the chest. The results indicate that Irwin's protocol has a high diagnostic accuracy in this group of patients.

\section{MATERIALS AND METHODS}

The files of all patients referred to a single physician ( $\mathrm{VH}$ ) for evaluation of chronic cough were examined. Only those patients who satisfied the following criteria were selected: lifelong nonsmokers, normal radiograph of the chest, and cough lasting longer than four weeks being the sole presenting complaint. There were 228 patients who fulfilled these criteria, of whom 198 returned for follow-up; no attempt was made to trace the remaining 30 patients.

\section{Investigations}

The diagnostic protocol included the following investigations: chest x-rays, pulmonary function tests, histamine inhalation challenge test, barium swallow, radiographs of the sinuses, sputum cultures, exercise-induced asthma test and fibreoptic bronchoscopy. Although chest x-ray and pulmonary function tests were done in all patients before their first clinical assessment, other investigations were based on clinical judgement. A barium swallow was ordered if: there were symptoms suggestive of gastroesophageal reflux (heartburn, acid taste in the mouth, nocturnal cough); noninvasive investigations failed to establish a specific diagnosis; or there was no response to therapeutic trials consisting of inhaled or intranasal corticosteroids, beta-adrenergic agents or antihistamines. Histamine inhalation challenge test was ordered if the clinical history suggested asthma, and spirometry was either normal or did not demonstrate reversibility after administration of inhaled salbutamol. Sinus x-rays were ordered if history and physical examination suggested chronic sinusitis and/or postnasal drip. Fibreoptic bronchoscopy was usually reserved for patients with negative noninvasive investigations and no response to empirical therapy as listed above, including oral corticosteroids. Unless clinical judgment dictated otherwise, the order of investigations was: chest x-ray, pulmonary function tests, histamine challenge test, exercise-induced asthma test, barium swallow, sinus $\mathrm{X}$-rays and fibreoptic bronchoscopy.

Pulmonary function tests included maximum expiratory flow-volume curve, body plethysmography and single-breath diffusing capacity for carbon monoxide (DCO). Maximum expiratory flow-volume curves were obtained with patients seated and nose clips in place using CPI 220 dry rolling seal spirometer (Cardio-Pulmonary Instruments, Texas) interfaced with an X-Y recorder (HP7045B, Hewlett-Packard Corp) equipped with a $1 \mathrm{~s}$ timer for measurement of forced expiratory volume $\left(\mathrm{FEV}_{1}\right)$. Three reproducible $( \pm 5 \%)$ curves were obtained, and one with the greatest sum of FEV 1 and forced vital capacity (FVC) was selected for analysis (6). Maximum expiratory flow rates at $50 \%$ and $75 \%$ of exhaled vital capacity ( $\dot{V}_{50}$ and $\dot{V}_{25}$, respectively) and inspiratory capacity were computed from this curve. Functional residual capacity (FRC) and airway resistance were measured in a variable pressure, constant volume body plethysmograph (OHIO 3000 system, Ohio Instruments, Wisconsin) using standard techniques (7). Total lung capacity (TLC) was obtained by adding inspiratory capacity to FRC. Residual volume (RV) was obtained by subtracting FVC from the TLC. Single breath diffusing capacity for carbon monoxide was measured using helium as the carrier gas and a breath-holding time of $10 \mathrm{~s}$ (HP 47305A system, Hewlett-Packard Corp). Predicted values for TLC, RV and vital capacity were taken from Goldman et al (8), for FEV $1 / F V C$ from Morris et al (9), for $\dot{V}_{50}$ and $\dot{V}_{25}$ from Lapp et al (10), and for DCO from Gaensler et al (11).

Histamine challenge test was done in accordance with the protocol described by Hargreave et al (12). The aerosol was administered using a Wright nebulizer with $3 \mathrm{~mL}$ of solution in the container operating at a flow rate to produce an aerosol output of 0.13 to $0.15 \mathrm{~mL} / \mathrm{min}$. It was inhaled for $2 \mathrm{mins}$ during tidal breathing. The initial concentration of histamine was $0.03 \mathrm{mg} / \mathrm{mL}$. The dose was doubled until either FEV 1 dropped by at least $20 \%$ from the baseline value, or a histamine concentration of $16 \mathrm{mg} / \mathrm{mL}$ was reached. An exerciseinduced asthma test, performed only if clinical judgement suggested asthma in the presence of normal pulmonary function and histamine challenge tests, was done according to the standard protocol $(13,14)$ with $\mathrm{FEV}_{1}$ measured immediately before the exercise, and 5. 15 and 30 mins after exercise.

Barium swallow and x-rays of the sinuses were performed and interpreted by the radiologist without detailed knowledge of patients' clinical history. 
TABLE 1

\section{Characteristics of the study population}

\begin{tabular}{lc} 
Total number of patients & 228 \\
$\begin{array}{l}\text { Number of patients who returned for final } \\
\text { follow-up visit }\end{array}$ & 198 \\
Male:female & $83: 115$ \\
Age (mean \pm SD) & $47 \pm 17$ \\
Duration of cough (months: mean \pm SD) & $25 \pm 35$ \\
Final follow-up visit since the initial visit & $3 \pm 5$ \\
(months: mean \pm SD) & \\
\hline
\end{tabular}

SD Standard deviation

\section{Specific diagnoses and therapy}

The diagnosis of asthma was established either by spirometry (20\% or greater improvement in $\mathrm{FEV}_{1}$ following inhalation of $200 \mu \mathrm{g}$ of salbutamol in the pulmonary function laboratory, provided the initial FEV 1 was lower than $80 \%$ of predicted value), or by a positive histamine challenge test (20\% or greater reduction in $\mathrm{FEV}_{1}$ at a histamine concentration lower than or equal to $16 \mathrm{mg} / \mathrm{mL}$ ). The treatment consisted of inhaled corticosteroids (beclomethasone 400 to $3000 \mu \mathrm{g}$ daily or budesonide 400 to $2400 \mu \mathrm{g}$ daily), betaadrenergic agents (salbutamol 100 to $1200 \mu \mathrm{g}$ daily), and anticholinergic agents (ipratropium bromide $160 \mu \mathrm{g}$ daily); the above agents were used either alone or in combination.

Gastroesophageal reflux was diagnosed based on the barium swallow demonstrating either spontaneous or induced reflux. The treatment included avoidance of food for $3 \mathrm{~h}$ before bedtime, elevation of the head of bed on 6 inch blocks, a prokinetic agent (metoclopramide or domperidone) taken 15 mins before the evening meal, and an $\mathrm{H}_{2}$-receptor antagonist (ranitidine or famotidine).

Postnasal drip was diagnosed by history, nature of cough (ie, throat clearing), physical examination of the pharynx (ie, cobblestone appearance of pharyngeal mucosa, purulent or mucoid exudate adherent to posterior pharynx), normal pulmonary function and histamine challenge tests. The treatment in most cases included a long-acting antihistamine (loratadine or astemizole $10 \mathrm{mg}$ daily) and intranasal corticosteroid (beclomethasone 200 to $400 \mu \mathrm{g}$ daily or flunisolide 100 to $200 \mu \mathrm{g}$ daily); in those with a history of purulent nasal discharge, a course of oral antibiotics was also prescribed.

Postinfectious cough was diagnosed on the basis of history of lower respiratory tract infection at the time of the onset of cough and negative histamine challenge test. It was treated with high doses of inhaled corticosteroids (beclomethasone 1500 to $2000 \mu \mathrm{g}$ daily or budesonide 1200 to 1600 $\mu \mathrm{g}$ daily).

In all cases the patients were asked to stay on specific treatment for two months before returning for a follow-up visit. The correctness of the diagnosis was confirmed by assessing the clinical response to therapeutic trials. Depending on the difficulty in establishing the final diagnosis and adequacy of clinical response to the specific treatment, the patients were seen in follow-up from two to eight times.
TABLE 2

Clinical features

\begin{tabular}{lc}
\hline & $\begin{array}{c}\text { Number (\%) of } \\
\text { patients }\end{array}$ \\
\hline Attributes of cough & $97(49 \%)$ \\
Preceded by upper respiratory infection & $97(49 \%)$ \\
Nocturnal & $90(46 \%)$ \\
Exercise-induced & $82(41 \%)$ \\
Aggravated by breathing cold air & $67(34 \%)$ \\
Associated with wheezing & $54(27 \%)$ \\
Associated with chest tightness & $62(31 \%)$ \\
Associated with sputum production & \\
Medical history & $92(47 \%)$ \\
None - healthy & $24(17 \%)$ \\
Allergies & $48(24 \%)$ \\
Heartburn & $48(24 \%)$ \\
History of sinusitis or postnasal drip & $28(14 \%)$ \\
Hypertension & $18(9 \%)$ \\
On ACE inhibitor & $7(4 \%)$ \\
History of asthma &
\end{tabular}

*Percentage of patients is based on the 198 patients who returned for follow-up. ACE Angiotensin-converting enzyme inhibitor

\section{Data analysis}

The data obtained from patients' files were grouped into three main categories: initial clinical assessment, which consisted of tabulating the results of history, physical examination and recording the frequencies of initial diagnoses; objective investigations, which included results of investigations listed above; final clinical assessment, which included the response to treatment, the final diagnosis, and the concordance between the initial and final diagnoses.

\section{RESULTS}

In accordance with the methods of assessment, the results were grouped into three categories: clinical data obtained during the initial visit; outcome of laboratory investigations; and clinical data obtained during the final visit.

\section{Clinical data obtained during the initial visit}

The 228 patients (139 females, 89 males) all had longstanding cough lasting from two months to 18 years; 198 returned for final follow-up visit after an average of $3 \pm 5$ months from the time of their initial visit (Table 1). In 88 patients the duration of cough was two to six months, in 31 patients it was six to 12 months, in 24 patients it was 12 to 24 months, and in 56 patients the duration of cough was greater than 24 months.

Table 2 summarizes the clinical features elicited during the initial interview. Upper respiratory infection, occurring within four to nine months before the initial visit, was present in $49 \%$ of patients. Many patients reported symptoms suggestive of hyperreactive airways, with cough precipitated or aggravated by exercise, breathing cold air, associated with wheezing, or chest tightness. Although $31 \%$ of patients re- 
TABLE 3

Results of pharyngeal and chest examination

\begin{tabular}{lc}
\hline Finding & Number (\%) of patients* \\
\hline Pharynx & $130(66 \%)$ \\
Normal & $34(17 \%)$ \\
Inflamed posterior wall & $29(15 \%)$ \\
$\begin{array}{l}\text { Cobblestone appearance of } \\
\text { mucosa }\end{array}$ & $5(3 \%)$ \\
Exudate adherent to pharyngeal & \\
$\quad$ walls & $3(2 \%)$ \\
Inflamed tonsils & $3(2 \%)$ \\
Other & \\
Chest & $81(41 \%)$ \\
Normal & $92(46 \%)$ \\
Forced expiratory wheezes & $14(7 \%)$ \\
Wheezes during tidal breathing & $9(5 \%)$ \\
Crackles & $8(4 \%)$ \\
Other &
\end{tabular}

"Percentage of patients is based on the 198 patients who returned for follow-up

ported that their cough was associated with sputum production, by the time they were seen in the office the amount of expectorated sputum was minimal; in fact, most patients were unable to submit a satisfactory sputum specimen for bacterial cultures, cytological examination or eosinophil count.

Most of the patients (47\%) were completely healthy before the onset of cough. Many had a history of sinusitis, post nasal drip or heartburn, although only $3 \%$ had a documented hiatus hernia. Many patients had a history of hypertension, but only $9 \%$ were on angiotensin-converting enzyme (ACE) inhibitors for control of their blood pressure.

Pharyngeal examination (Table 3) was normal in $66 \%$ of patients. In the remaining group the findings consisted of inflamed posterior pharyngeal wall, cobblestone appearance of pharyngeal mucosa, exudate or mucus adherent to the posterior pharyngeal wall, and enlarged or inflamed tonsils.

Chest examination (Table 3 ) was completely normal in $41 \%$ of patients. Unequivocally abnormal findings, such as wheezes or crackles present during tidal breathing, were heard in 5 to $7 \%$ of patients. Wheezes on forced expiration, which may be a normal finding, were common.

\section{Outcome of laboratory investigations}

Pulmonary function studies: Maximum expiratory flowvolume curves were normal in 152 patients, lung volumes were normal in 126 patients, and $D_{\text {co }}$ was normal in 164 patients. Peripheral airways obstruction, defined as measured $\grave{V}_{50} / \mathrm{FVC} 0.5$ or less, or measured $\dot{\mathrm{V}}_{25} /(\mathrm{FVC} / 2) 0.5$ or less was present in 41 patients (21\%). More significant airway obstruction, defined as reduction in $\mathrm{FEV}_{1}$ by at least $20 \%$ from the predicted value was present in five patients (3\%). Hyperinflation (measured TLC $120 \%$ or greater of the predicted value) and air trapping (measured RV/TLC $120 \%$ or greater of the predicted value) was present in 51 patients (25\%). Lung restriction (measured TLC $80 \%$ or less of the predicted value) was present in 21 patients (11\%). DCo was
TABLE 4

Results of laboratory investigations

\begin{tabular}{lcc}
\hline Test & $\begin{array}{c}\text { Number of } \\
\text { patients }\end{array}$ & $\begin{array}{c}\text { Number (\%) } \\
\text { abnormal }\end{array}$ \\
\hline Flow-volume curve & 197 & $46(23 \%)$ \\
Lung volumes & 198 & $72(36 \%)$ \\
Single breath Dco & 198 & $34(17 \%)$ \\
Response to & 82 & $8(10 \%)$ \\
$\quad$ bronchodilator & 143 & $24(17 \%)$ \\
Histamine challenge & 15 & $0(0 \%)$ \\
Exercise-induced asthma & 198 & $0(0 \%)$ \\
Radiograph of the chest & 24 & $7(29 \%)$ \\
Radiograph of the sinuses & 67 & $55(82 \%)$ \\
Barium swallow & 16 & $1(6 \%)$ \\
Bronchoscopy & &
\end{tabular}

Dco Diffusing capacity for carbon monoxide

reduced to less than $75 \%$ of the predicted value in 34 patients (17\%). In 82 patients maximum expiratory flow-volume curves were repeated after inhalation of bronchodilator; only eight patients (10\%) demonstrated more than 20\% improvement in $\mathrm{FEV}_{1}$ or more than $50 \%$ improvement in $\mathrm{V}_{50}$.

Histamine inhalation challenge was performed in 143 patients. In the remaining 55 patients it was not done because the correct diagnosis was established by other means, and the test was thought to be clinically unnecessary. In 119 patients the test was normal, ie, reduction in $\mathrm{FEV}_{1}$ by less than $20 \%$ at a histamine concentration of $16 \mathrm{mg} / \mathrm{mL}$. Twenty-four patients had more than $20 \%$ reduction in $\mathrm{FEV}_{1}$ at a histamine concentration of less than $16 \mathrm{mg} / \mathrm{mL}$, indicative of airway hyperreactivity; the average ( \pm standard deviation) reduction in $\mathrm{FEV}_{1}$ was $24 \pm 4 \%$ at a histamine concentration of $10 \pm 6$ $\mathrm{mg} / \mathrm{mL}$. Exercise-induced asthma test, performed in 15 patients, was negative in all.

Radiological studies: Barium swallow (Table 4) was performed in 67 patients. It was abnormal in 55 of them, demonstrating hiatus hernia and gastroesophageal reflux in all but two: one patient had esophageal diverticulum and the other had presbyesophagus. Hiatus hernia without gastroesophageal reflux was demonstrated in only four patients.

Sinus X-rays were done in 24 patients whose history suggested purulent sinusitis. They were normal in 17 patients; the remaining seven patients had sinusitis, retention cysts, polyps, or an abscess.

Bronchoscopy: Fibreoptic bronchoscopy was done in 16 patients; endobronchial tuberculosis was diagnosed in one of them, while the rest of the patients had normal bronchi, negative bacterial and fungal cultures, no endobronchial lesions, and negative cytology. The patient with endobronchial tuberculosis was a 66-year-old woman who had had a cough for five years. Her only distinguishing features were Eastern European background, age older than the mean for the group, and positive tuberculin skin test.

\section{Clinical data obtained during final visit}

Diagnosis: Based on the positive findings of the diagnostic investigations and a beneficial response to therapeutic trials, 


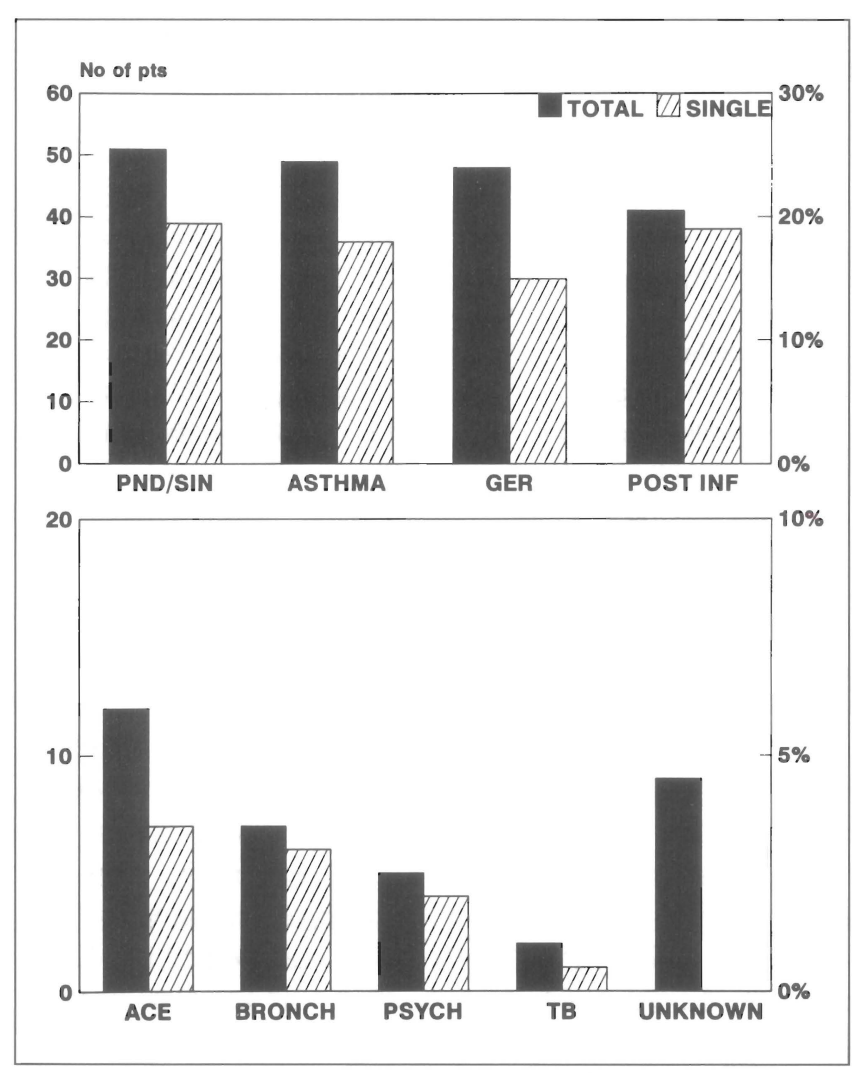

Figure 1) Frequency of different diagnoses occurring either alone (SINGLE) or in combination with others (TOTAL) in 198 patients. ACE Angiotensin-converting enzyme inhibitor; BRONCH Bronchitis; GER Gastroesophageal reflux; PND/SIN Postnasal drip/sinusitis; POST INF Postinfectious cough; PSYCH Psychogenic cough; TB Tuberculosis

a specific diagnosis was considered to be definitively established in 180 of 198 who returned for follow-up. In nine patients (four males, five females; age range 27 to 69 years; duration of cough two to 216 months) either diagnostic investigations were positive suggesting a specific diagnosis, or the clinical history and physical examination permitted a specific diagnosis to be made, but this diagnosis could not be sustained at follow-up due to the lack of beneficial response to specific therapy (Figure 1). In nine additional patients (two males, seven females; age range 22 to 73 years; cough duration five to 66 months) the diagnosis could not be established despite all of the investigations summarized in Table 4 and multiple therapeutic trials. The five most common diagnoses (postnasal drip, postinfectious cough, asthma, gastroesophageal reflux, and ACE inhibitor-induced cough) alone or in combination accounted for cough in 176 of 198 patients $(89 \%)$.

The clinical diagnostic accuracy and the value of investigations may be inferred by comparing the initial with the final diagnosis in each patient. The initial diagnosis is based strictly on clinical impression, without the benefit of diagnostic investigations and therapeutic trials. It may therefore be expected that initially fewer single diagnoses are made than during the final visit. Furthermore, the initial and final diagnoses may not be the same. It was found that during the initial

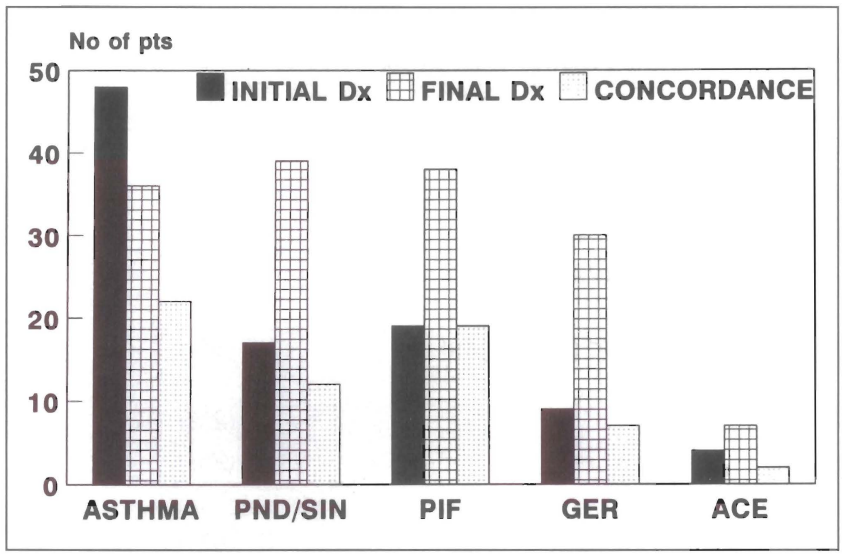

Figure 2) Diagnostic value of initial clinical impression in 198 patients. INITIAL Dx-Number of patients with initial diagnosis; FINAL Dx - Number of patients with the same final diagnosis; CONCORDANCE - Number of patients with identical initial and final diagnosis; only single, rather than multiple, diagnoses are shown. ACE Angiotensin-converting enzyme inhibitor; GER Gastroesophageal reflux; PND/SIN Postnasal drip/sinusitis; PIF Postinfectious cough

assessment a single initial diagnosis was made in $55 \%$ of the patients, whereas during final assessment a single final diagnosis was made in $86 \%$ of the patients; $13 \%$ had two diagnoses and $1 \%$ had three.

How well the initial and final diagnoses agreed is illustrated in Figure 2. For each specific diagnosis, this figure shows the number of patients in whom this diagnosis was made during the initial visit, during the final visit, and the concordance between the two visits (ie, the number of patients in whom the initial and the final diagnoses were identical). Ideally, if the initial diagnosis is correct in all patients, the three bars should have the same height. This is obviously not the case. Other than asthma, the correct cause of cough was always underdiagnosed during the initial visit, although in most cases it was sustained during final follow-up.

Asthma was the most difficult disease to diagnose. It was overdiagnosed initially and sustained at final follow-up visit in only $50 \%$ of the patients. On the other hand, postinfectious cough was sustained in all patients in whom it was diagnosed initially. The initial diagnosis of postnasal drip and gastroesophageal reflux was sustained in $71 \%$ and $78 \%$ of the patients, respectively.

Outcome: The outcome, assessed during the final visit, revealed that in 180 patients the cough improved or resolved; improvement was defined subjectively by the patient him/herself, who expressed a view that cough no longer constituted a problem requiring medical attention. In 18 patients ( 10 males, 13 females; age $46 \pm 15$ years; duration of cough $42 \pm 56$ months) it was unchanged. In nine patients, the final diagnosis was strongly suggested by history, physical examination or abnormal investigations (postnasal drip three, gastroesophageal reflux - four, psychogenic - one, and asthma - one). One of the patients refused all investigations after the initial chest $\mathrm{x}$-ray and pulmonary function tests, and another one admitted to being noncompliant with treatment 
TABLE 5

Outcome of specific therapy in patients with chronic cough*

\begin{tabular}{|c|c|c|c|}
\hline \multirow[b]{2}{*}{ Final diagnosis } & \multicolumn{3}{|c|}{ Outcome } \\
\hline & Improved & Resolved & Unchanged \\
\hline Asthma & 9 & 26 & 1 \\
\hline Gastroesophageal reflux & 9 & 18 & 3 \\
\hline Postinfectious & 12 & 26 & 1 \\
\hline Postnasal drip & 11 & 25 & 3 \\
\hline ACE inhibitor & 1 & 6 & 0 \\
\hline Other & 7 & 2 & 1 \\
\hline Unknown & 1 & 0 & 8 \\
\hline Total & 50 & 103 & 17 \\
\hline
\end{tabular}

*Patients with single diagnosis only. ACE Angiotensin-converting enzyme

for gastroesophageal reflux demonstrated on a barium swallow. In the remaining seven patients specific treatment and empirical therapeutic trials were unsuccessful. It is possible that these patients were either noncompliant with the specific treatment prescribed, or the diagnosis was incorrect, or the treatment was inappropriate. Depending on whether these patients were included or excluded from the group in whom the correct diagnosis was considered to be established, results indicate that the correct diagnosis can be achieved in 91 to $95 \%$ of patients.

Of the nine patients who remained undiagnosed, all were seen in follow-up from four to 22 months after the initial visit. In one of them the cough improved spontaneously, while in the remaining eight it was unchanged. None of them developed an overt disease that could account for their cough. None of these patients had emotional factors to permit the diagnosis of psychogenic cough.

The relationship between treatment and specific final diagnosis is summarized in Table 5. In none of the patients cough worsened during the study period.

\section{DISCUSSION}

This study indicates that following an orderly diagnostic and therapeutic protocol as described by Irwin et al (1), most nonsmoking patients with normal chest radiographs and prolonged cough can be diagnosed and treated successfully.

A clinical study such as the present one has several inherent limitations, which must be addressed before discussing the present results in the context of previous investigations.

First, the patient population described is not representative of what may be seen by a general practitioner, but probably reflects closely the type of patient referred to a pulmonary specialist. Consequently, the relative frequencies of diagnostic categories may be different in another patient population: for example, postinfectious cough, which is self-limited in a majority of patients, will probably be seen more frequently in general practice than among patients referred to a specialist, but the categories themselves will most likely remain the same.
Second, not all tests were done in all patients; investigations were ordered sequentially, and if following a positive test the prescribed therapy was successful, no further investigations were carried out. If, on the other hand, despite a positive test and proper treatment the patient continued to complain of cough, other investigations were carried out and/or treatment was modified. Nevertheless, it is possible, although unlikely, that there was a larger subgroup of patients who might fit several specific diagnostic groups.

Third, it soon became clear that some specific investigations have a very low yield, and therefore were ordered infrequently, and only if the pretest clinical probability of a positive result was high. For example, initially many patients had complete blood counts because of suspected leucocytosis, abnormal differential counts and elevated erythrocyte sedimentation rate. It soon became apparent that these tests were invariably normal, and they were no longer ordered. Similarly, sputum cultures were ordered initially for all patients, but the great majority of them either could not produce any sputum or produced unsatisfactory specimens - saliva or specimens with abundant epithelial cells. The most relevant example is probably sinus $\mathrm{x}$-rays. They are almost always negative in the population described here, and, in this author's opinion, do not influence the diagnosis of postnasal drip.

Fourth, one of the outcome criteria - 'cough improved' is imprecise. Clearly, this is a subjective criterion, based on the patient's perception. We considered using an analogue scale to grade the improvement, but decided against it in order to keep the number of outcome categories small and simple. As mentioned above, the improvement in cough, although not quantified, was significant from a patient's point of view because it was no longer considered a problem.

Fifth, it may be argued that cough is frequently self-limited and resolves without treatment, rendering the diagnostic protocol unnecessary. This is certainly true in general practice, but not in specialized practice; in all our patients cough lasted more than one month, and in most of them appreciably longer.

With the above limitations, how do the present results compare with previous investigations testing Irwin's protocol in other patient populations? It is remarkable that, although cough in nonsmoking adults is a very common clinical problem, there are only four clinical studies in adults $(2,4,5,17)$ that address this issue and could be compared with the present investigation. The major differences between them and the present study are: larger number of patients (198 in this study versus 102 studied by Irwin et al [5] and 139 studied by Poe et al [4]); more uniform patient population, which did not include any smokers or patients with chest x-ray abnormalities; and the retrospective, rather than prospective nature of the present study. The latter point is probably the most important one preventing a full comparison with the previous studies. However, similar to the prospective studies, the patients reviewed here were unselected (although not consecutive); the only criteria for entry were cough lasting longer than four weeks, normal chest x-ray and no history of smok- 
TABLE 6

Comparison with previous studies

\begin{tabular}{lrcc}
\hline & Irwin (4) & Poe (3) & Present \\
\hline Diagnostic success rate (\%) & 98 & 88 & 91 \\
Single versus multiple diagnoses (\%) & & \\
One diagnosis & 73 & 83 & 86 \\
Two diagnoses & 23 & 4 & 13 \\
Three or more diagnoses & 3 & 0 & 1 \\
Unknown & 1 & 12 & 5 \\
Frequency of specific causes (\%) & & & \\
(alone or in combination) & & & \\
Asthma & 24 & 33 & 25 \\
Postnasal drip & 41 & 28 & 26 \\
Postinfectious & - & 11 & 21 \\
Chronic bronchitis & 5 & 7 & 2 \\
Gastroesophageal reflux & 21 & 6 & 24 \\
Drug-induced & 2 & 0 & 6 \\
Psychogenic & 0 & 1 & 2 \\
Outcome of specific therapy (\%) & & & \\
Resolution & 98 & 45 & 57 \\
Improvement & 0 & 39 & 31 \\
No change & 2 & 12 & 12 \\
\hline
\end{tabular}

ing. We tried to avoid rejection of any patients who satisfied these criteria, thus reducing bias.

Despite these methodological differences, the findings of the different studies are remarkably similar (Table 6). First, the diagnosis can be established in the majority of patients ( 88 to $98 \%$ ). Second, in most patients the cough is due to a single cause (73 to $86 \%$ ). Third, asthma and postnasal drip are the two most common diagnoses, responsible for majority of the chronic cough. Finally, the outcome of specific therapy is very good: 84 to $98 \%$ of patients manifest either complete resolution or improvement.

Differences in the diagnostic classification of cough employed by various authors are probably responsible for some of the divergent results observed in different studies. The final diagnosis is to some extent subjective, and it is not surprising that different investigators may not agree on the specific diagnosis.

A case in point is asthma. Irwin et al (5) diagnosed asthma based on beneficial response to specific therapy and a positive methacholine challenge test. Poe et al (4) used clinical criteria in some patients and carbachol challenge test in others. We defined asthma by demonstrating either postbronchodilator reversibility or positive histamine challenge test, which eliminated some of the subjectivity.

Another example is postinfectious cough. This is a subjective diagnosis, arrived at only by history. The diagnosis may be easily confused with asthma, but the histamine challenge test in this case is negative. It is differentiated from postnasal drip because the character of the cough and the pharyngeal examination are different. The cough is not throat-clearing, but more 'tracheal', the pharyngeal mucosa does not have a cobblestone appearance, there are no mucoid or purulent secretions adherent to the posterior pharyngeal wall, and there is no response to antihistamines and intranasal corticosteroids. Poe et al (4) had similar cases, but none of the patients studied by Irwin et al $(2,5)$ fell into this category.

In a relatively large proportion of patients in our study (24\%) gastroesophageal reflux was the major reason for cough. The causal relationship between gastroesophageal and chronic cough is well described $(2,4,5,16)$. The frequency of 'silent' gastroesophageal reflux is not surprising given that when reflux is the cause of chronic cough, it may be silent up to $43 \%$ of the time (15). In the present study 10 of 30 patients with gastroesophageal reflux as the sole reason for cough had no clinical features to suggest this diagnosis. Since barium swallow is not a sensitive test for the diagnosis of gastroesophageal reflux, it is possible that had we performed esophageal $\mathrm{pH}$ monitoring, the frequency of gastroesophageal reflux would have been even higher.

Based on the results of the present study, the following strategy for the investigation of chronic cough is recommended. All patients should have pulmonary function tests. If the $\mathrm{FEV}_{1}$ is reduced, spirometry should be repeated after inhalation of bronchodilator. If the $\mathrm{FEV}_{1}$ is normal, a histamine challenge test should be performed. This permits us to identify all patients with asthma and to concentrate on therapeutic trials of bronchodilator or anti-inflammatory inhalers. If the histamine challenge test is negative and the history does not suggest postinfectious cough, a trial of antisinusitis therapy is indicated; if the history suggests postinfectious cough, a trial of high dose inhaled corticosteroids is indicated. Only if these therapeutic trials are not successful should other tests such as barium swallow (or preferably esophageal pH monitoring) or bronchoscopy be contemplated. Similar to others (17), bronchoscopy was found to be of minimal diagnostic value, perhaps because all patients studied here were nonsmokers; none had endobronchial cancer and only one patient had endobronchial tuberculosis.

We conclude that:

- the majority, but not all, of patients with chronic cough can be diagnosed, successfully treated, and cured using the protocol first described by Irwin (1);

- the main causes of cough in nonsmoking adults with normal chest radiograph are relatively 'benign', eg, postnasal drip, postinfectious cough or asthma, rather than more serious such as malignancy, tuberculous, or fungal infection;

- combination of simple procedures (clinical interview/examination, pulmonary function tests, histamine challenge test, and barium swallow) will enable diagnosis in the majority of patients;

- the yield from invasive procedures such as bronchoscopy is very low.

Finally, not all patients with chronic cough may be successfully diagnosed and treated. This suggests the existence of other factors, unsuspected and not included in Irwin's (1) protocol, in these patients. 


\section{REFERENCES}

1. Irwin RS, Rosen MJ, Braman SS. Cough: A comprehensive review. Arch Intern Med 1977; 137:1186-91.

2. Irwin RS, Corrao WM, Pratter MR. Chronic persistent cough in the adult: The spectrum and frequency of causes and successful outcome of specific therapy. Am Rev Respir Dis 1981;123:413-7.

3. Smyrnios NA, Irwin RS. Chronic cough. Curr Pulmonol 1993;14:73-93.

4. Poe RH, Harder RW, Israel RH, Kallay MC. Chronic persistent cough: Experience in diagnosis and outcome using an anatomic diagnostic protocol. Chest 1989;95:723-8.

5. Irwin RS, Curley FJ, French CL. Chronic cough: The spectrum and frequency of causes, key components of the diagnostic protocol, and outcome of specific therapy. Am Rev Respir Dis 1990;141:640-7.

6. ATS statement - Snowbird workshop on standardization of spirometry. Am Rev Respir Dis 1979;119:831-8.

7. DuBois AB, Botelho SY, Bedell GN, Marshall R, Comroe JH Jr. A rapid method for measuring thoracic gas volume: Comparison with a nitrogen washout method for measuring functional residual capacity in normal subjects. J Clin Invest 1956;35:322-6.

8. Goldman HI, Becklake MR. Respiratory function tests: Normal values at median altitudes and the prediction of normal results. Am Rev Tuber Pulm Dis 1959;79:457-67.
9. Morris JF, Temple WP, Koski A. Normal values for the ratio of one-second forced expiratory volume to forced vital capacity. Am Rev Respir Dis 1973;108:1000-3.

10. Lapp NL, Hyatt RE. Some factors affecting the relationship of maximal expiratory flow to lung volume in health and disease. Dis Chest 1967;51:475-81.

11. Gaensler EA, Smith AA. Attachment for automated single breath diffusing capacity measurement. Chest 1973;63:136-45.

12. Hargreave FE, Ryan G, Thomson NC, et al. Bronchial responsiveness to histamine or methacholine in asthma; measurement and clinical significance. J Allergy Clin Immunol 1981;68:347-58.

13. Jones NL, Campbell EJM. Clinical exercise testing, 2nd edn, Philadelphia: WB Saunders Co, 1982.

14. Wasserman K, Hansen JE, Sue DY, Whipp BJ. Principles of exercise testing and interpretation. Malvern: Lea \& Febiger, 1987.

15. Irwin RS, Zawacki JK, Curley FJ, French CL, Hoffman PJ. Chronic cough as the sole presenting manifestation of gastro-esophageal reflux. Am Rev Respir Dis 1989;140:294-300.

16. Fitzgerald JM, Allen CJ, Craven MA, Newhouse MT. Chronic cough and gastroesophageal reflux. Can Med Assoc J 1989;140:520-4.

17. Poe RH, Israel RH, Utell MJ, Hall WJ. Chronic cough: Bronchoscopy or pulmonary function testing? Am Rev Respir Dis 1982;126:160-2. 


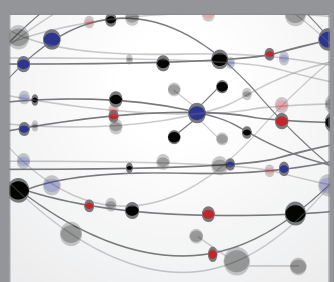

The Scientific World Journal
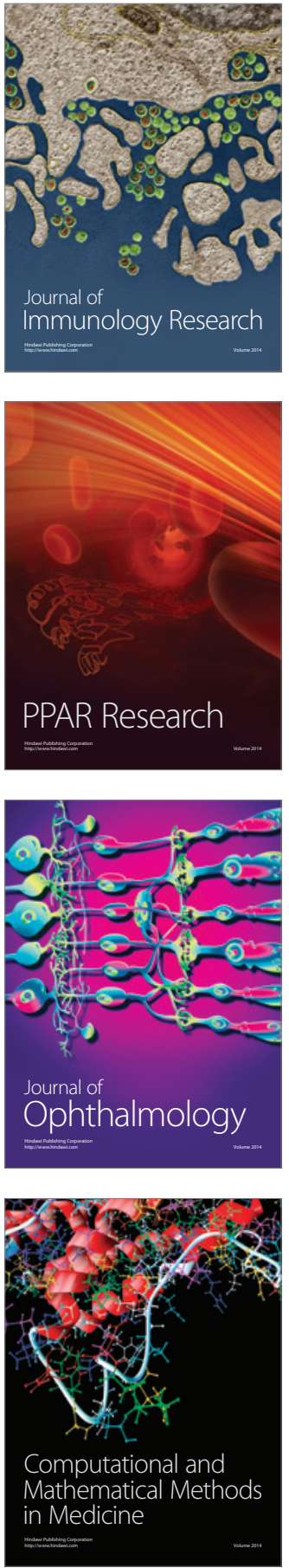

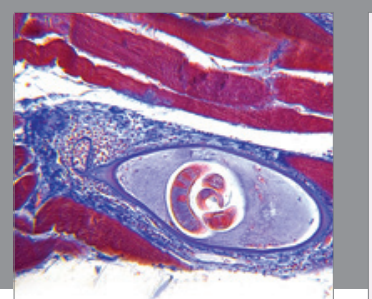

Gastroenterology Research and Practice

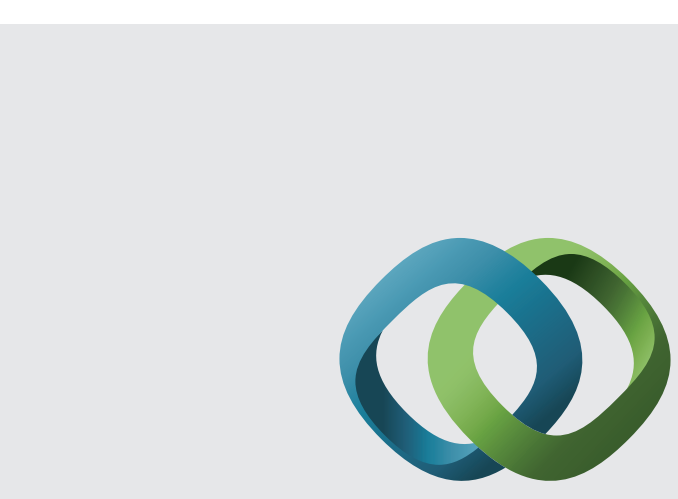

\section{Hindawi}

Submit your manuscripts at

http://www.hindawi.com
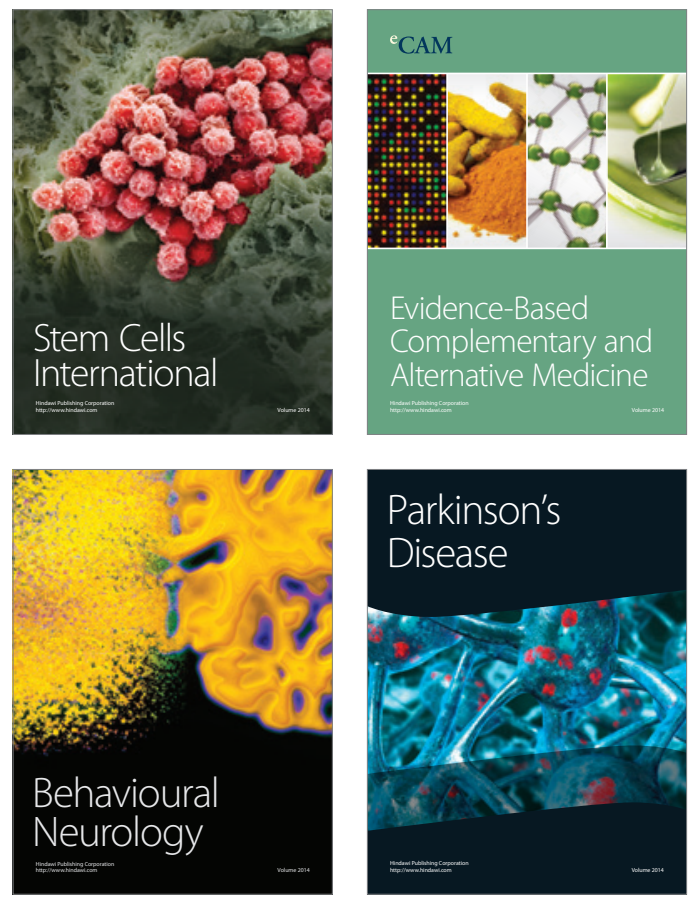
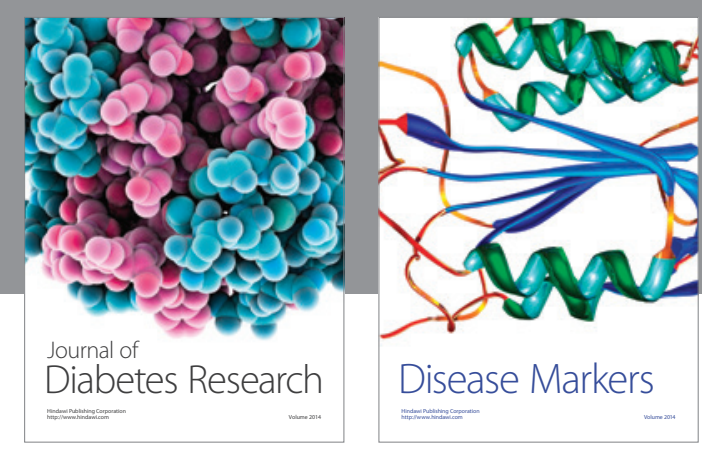

Disease Markers
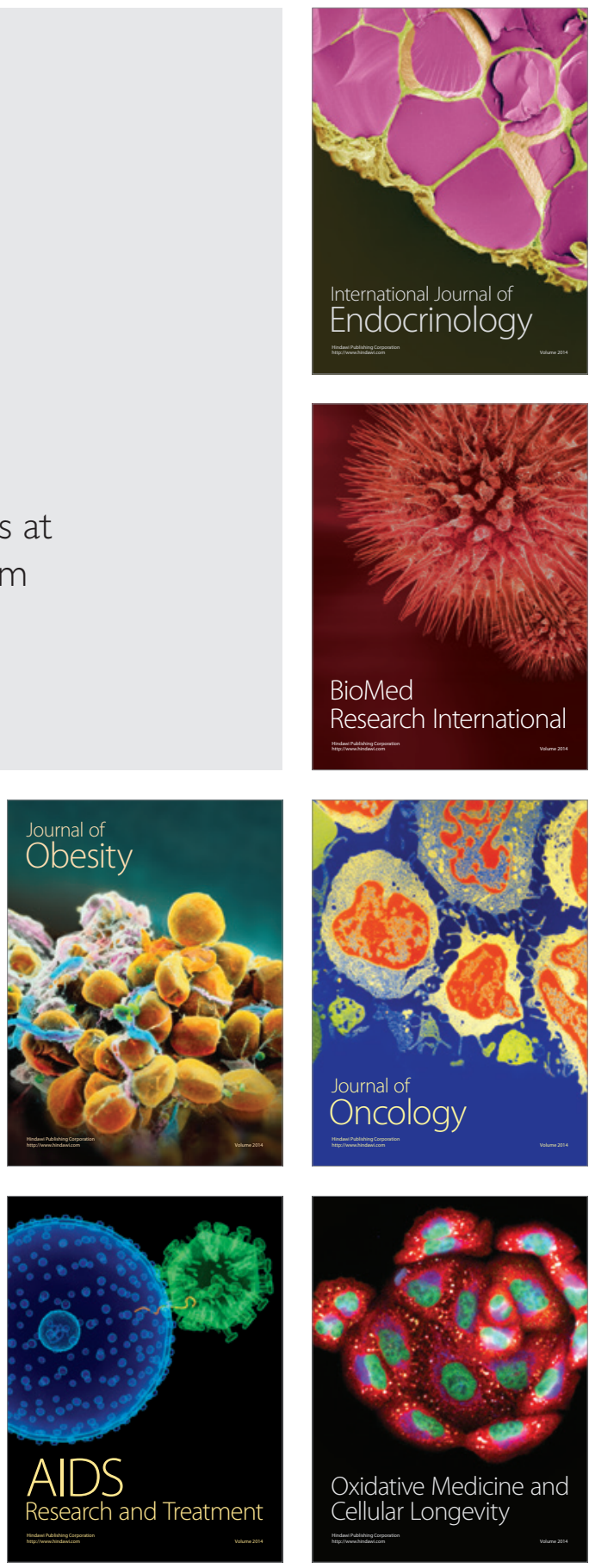